Provided for non-commercial research and education use. Not for reproduction, distribution or commercial use.

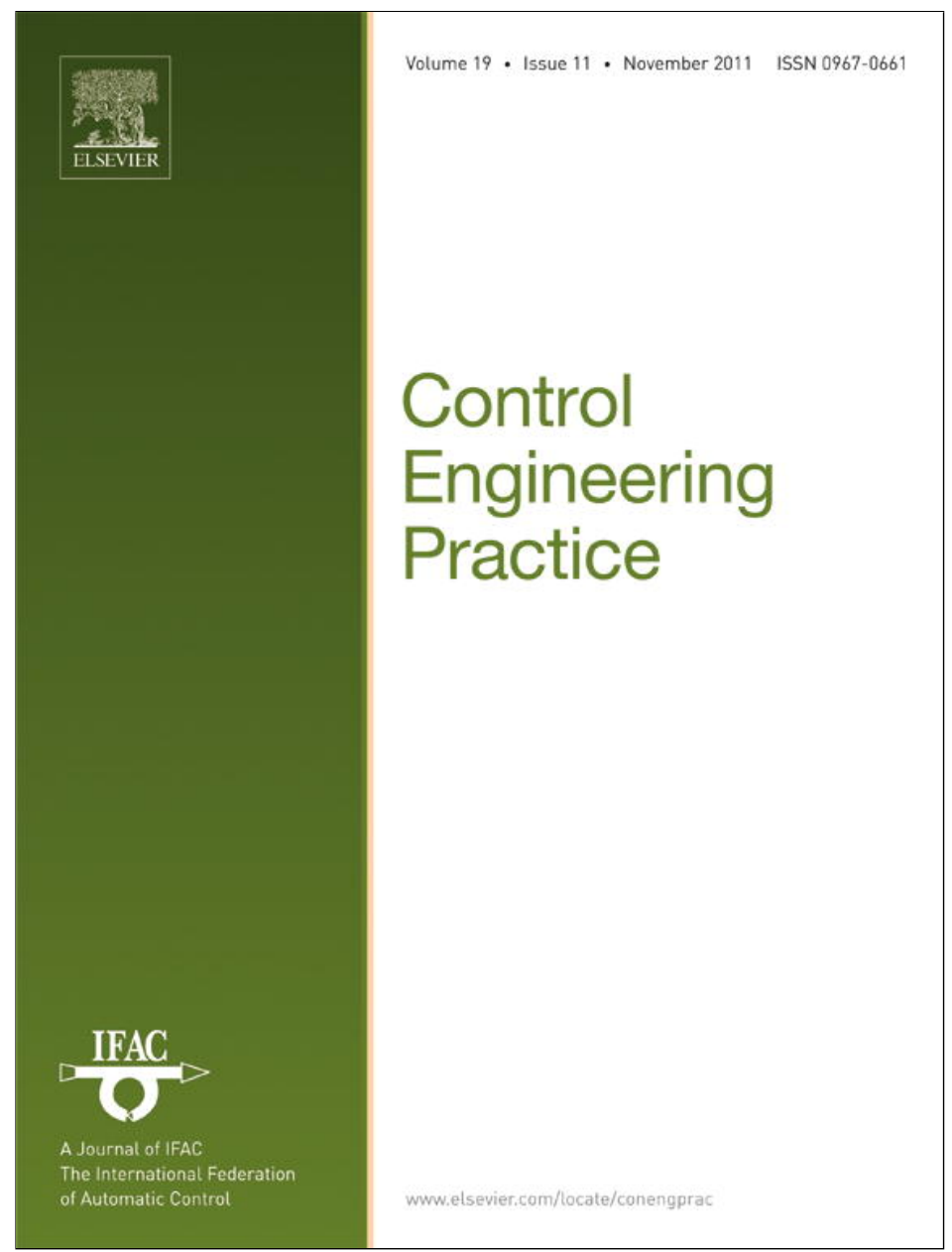

This article appeared in a journal published by Elsevier. The attached copy is furnished to the author for internal non-commercial research and education use, including for instruction at the authors institution and sharing with colleagues.

Other uses, including reproduction and distribution, or selling or licensing copies, or posting to personal, institutional or third party websites are prohibited.

In most cases authors are permitted to post their version of the article (e.g. in Word or Tex form) to their personal website or institutional repository. Authors requiring further information regarding Elsevier's archiving and manuscript policies are encouraged to visit:

http://www.elsevier.com/copyright 


\title{
Control of highly diluted combustion in Diesel engines
}

\author{
M. Hillion ${ }^{\mathrm{a}, \mathrm{b}}$, J. Chauvin ${ }^{\mathrm{a}, *}$, N. Petit ${ }^{\mathrm{b}}$ \\ a IFP Energies nouvelles, Control, Signal and Systems Department, 1 \& 4 Avenue de Bois Préau, 92852 Rueil Malmaison, France \\ ${ }^{\mathrm{b}}$ MINES ParisTech, Centre Automatique et Systèmes, Unité Mathématiques et Systèmes, 60 bd St Michel, 75272 Paris Cedex 06, France
}

\section{A R T I C L E I N F O}

Article history:

Received 26 February 2009

Accepted 13 June 2011

Available online 6 August 2011

Keywords:

Engine control

Highly diluted combustion

Cool flame

Combustion control

\begin{abstract}
A B S T R A C T
In this paper, an open-loop control strategy to improve the stability of highly diluted Diesel combustion during sharp transients is proposed. The main advantage of this open-loop method is that no additional in-cylinder sensor is required. The approach coordinates existing airpath and fuelpath controllers, and aims at accurately controlling the end of the cool-flame phenomenon. For this purpose, the injection time is adjusted based on an auto-ignition model and a cool-flame model. Both models are expressed under integral forms, named knock integral models. Experimental results obtained on a test bench and on-board a vehicle are presented. The results highlight the relevance of the approach in terms of combustion stability improvement, pollutant emissions and noise.
\end{abstract}

(c) 2011 Elsevier Ltd. All rights reserved.

\section{Introduction}

The control technology found on most Diesel automotive engines with Exhaust Gas Recirculation consists of two different loops: an airpath controller and a fuelpath controller. These subsystems aim at satisfying high-level orders from the driver (e.g. torque requests through the accelerator pedal). While the fuelpath controller handles the fuel injection system, the airpath controller primary task is to control the thermodynamic conditions in the intake manifold (pressure, temperature, and composition). Yet, convergence can take time, because the airpath subsystem is relatively slow (due to turbocharger inertia, actuator dynamics, pipe filling, ...).

During the frequent transients observed on-board vehicles, the temperature, the pressure, and the composition found in the cylinder are thus slightly different from optimally designed steady-state values. These offsets represent errors in initial conditions for the Diesel combustion process which, in this case of highly diluted combustion, is very sensitive. As a result, the combustion can produce high levels of noise and strong pollutant emissions, and possibly result in engine stall. Fortunately, this mismatch of initial conditions can be evaluated using commonly available sensors (located in the intake manifold) and dedicated observers. In this paper, a method to compensate initial in-cylinder conditions mismatch is proposed. It is now briefly sketched.

Usually, the fuelpath controller manages the injection time so that the combustion starts at an optimal instant. Assuming the

\footnotetext{
* Corresponding author. Tel.: +33147527417; fax: +33147527012.

E-mail addresses: mathieu.hillion@mines-paristech.fr (M. Hillion), jonathan.chauvin@ifpen.fr (J. Chauvin), nicolas.petit@mines-paristech.fr (N. Petit).
}

engine operates about steady-state, this guarantees an optimal combustion efficiency. In details, fuelpath controllers compute the injection time based on static look-up tables accounting for the current operating point. This approach assumes that the incylinder conditions match the setpoints of the current operating point. Unfortunately, this is obviously wrong during transients. The injection time has a major effect on the whole combustion timeline. Therefore, it is possible to use it to control the combustion process despite the mismatch in initial conditions. The remaining question is what is the right value for the injection time?

The contribution of this paper is as follows. To answer the previously formulated question, an auto-ignition model and a cool flame model are used. Both models take integral forms, referred to as "knock integral models". At first order, a sensitivity analysis provides a formula (controller) explicitly accounting for the discussed in-cylinder variables mismatch. An interesting feature of this formula is that it does not require any additional in-cylinder sensors, but solely uses data from commercial-line sensors. This methodology is applied both on a test bench engine and on-board a vehicle. Extensive tests are performed and stress the relevance of the approach in terms of pollutant emissions and noise production.

The paper is organized as follows. Section 1 presents the motivations for the considered problem and explains the combustion process. The combustion sensitivity to in-cylinder variables errors is detailed. In Section 2, models for the auto-ignition and the cool-flame phenomenon are presented. In Section 3, the combustion control problem is formulated using the previously introduced knock integral models. A solution at first order is derived. Its practical implementation is discussed in Section 4. In Section 5, test bench results are presented. Being representative of test driving cycles, they prove the validity of the concept of 
combustion control by means of coordination of the airpath controller and the fuelpath controller under both steady and transient conditions. In Section 6, actual vehicle implementation is presented. Pollutant and noise production results are discussed.

\section{Motivation}

\subsection{Highly diluted combustion in Diesel engines}

Pollution standards for automotive engines have steadily increased over the last decade and are now very stringent. Thus, reducing pollutant emissions from engines has become a topic of major interest in engine development and the car industry in general. Besides after-treatment technologies for exhaust gases (which are particularly expensive for Diesel engines), there has been a strong focus on developing cleaner combustion modes such as highly diluted combustion (Kahrstedt, Behnk, Sommer, \& Wormbs, 2003). In these modes, dilution is obtained by recirculating exhaust gases into the combustion chamber. A prime example is homogeneous combustion compression ignition ( $\mathrm{HCCl}$ ) which has attracted much attention (Milovanovic \& Chen, 2001). However, such combustion modes are relatively unstable and require efficient control strategies that incorporate both closed- and openloop laws (Walter \& Gatellier, 2003).

Consider a Diesel engine with Exhaust Gas Recirculation (EGR $\left.{ }^{1}\right)$. This set-up allows dilution of the air charge admitted into the cylinder with exhaust gases from previous combustion. This drastically reduces nitrogen oxide $\left(\mathrm{NO}_{x}\right)$ emissions by lowering the temperature peak during combustion. This EGR can be achieved using two different technologies. The first solution is external EGR (Chauvin, Corde, \& Petit, 2006). A pipe extracts exhaust gases from the exhaust line and introduces them into the intake line. The second approach is internal EGR (Chiang, Stefanopoulou, \& Jankovic, 2007). In this set-up, variable valve actuation (VVA) is used to allow exhaust gases to flow back into the cylinder during the intake phase or to be trapped in the cylinder after the exhaust phase. Although totally different in implementation, the two approaches yield similar beneficial effects on pollutant emissions. However, both can negatively affect the combustion stability.

Combustion occurs according to the timeline detailed in Fig. 1. There are two main phases corresponding to the airpath subsystem (which involves the intake and exhaust pipes, the intake and exhaust manifolds, the turbocharger(s), and the valve train) and the fuelpath subsystem (which consists of the injectors), as shown in Fig. 6.

To overcome the natural instability of the highly diluted combustion mode, accurate airpath and fuelpath controllers are required. These classic control systems are outlined in the following.

\subsection{Typical control system}

A complete nomenclature is given in Appendix A. In general engine set-ups, airpath and fuelpath controllers are used to guarantee that engine variables (pressure, composition, and injected fuel mass among others) track reference values.

Airpath controllers have long been used (Alfieri, Amstutz, \& Guzzella, 2008; Chauvin, Corde, \& Petit, 2006; Chauvin, Corde, \& Petit, 2007; Wang, 2008 and references therein). They result in efficient tracking of the intake manifold variables (reference pressure, reference air mass flow, burned gas rate (BGR), and

${ }^{1}$ Note that in this study, Exhaust Gas Recirculation (EGR) refers to the physical system (valve train or pipes) that permits to recirculate the exhaust gases, and burned gas rate (BGR) refers to the intake (or in-cylinder) variable, ranging from 0 to 1 , that represents the rate of burned gases mass. temperature of the intake charge) even during transients. The main actuators used are EGR valves, intake and exhaust throttles, turbocharger(s) and valve trains.

Typical fuelpath controllers can be described as follows. During the cylinder compression phase, fuel is injected and mixed with the compressed air and burned gas mixture. The fuel vaporizes and eventually auto-ignites after the so-called autoignition delay. Due to the high dilution, a cool flame is first present (Barba, Burkhardt, Boulouchos, \& Bargende, 2000; Chmela \& Orthaber, 1999; Reveille, Miche, Jay, \& Henriot, 2004) and then standard combustion occurs (Fig. 1). A classic fuelpath controller has the advantage of the fastness of a direct injection system, for which the parameters can be changed from one cycle to the next. Thus, it can be assumed that the injection parameters almost exactly track their setpoints.

This global control system, in which the airpath and fuelpath controllers operate without any particular coordination, is usually sufficient to provide stable combustion in the steady state and during quasi-static (i.e. slow) transients. However, the lack of coordination is problematic in actual vehicle implementation because of frequent sharp transients due to variations in driver torque demands $\left(\bar{T}_{q}\right)$ and engine speed $\left(N_{e}\right)$. Problems occur because these demands result in frequent transients for the reference airpath and fuelpath variables. Although both controllers work simultaneously, combustion stability is affected by performance differences between the airpath and fuelpath closed-loops.

\subsubsection{Sensitivity of combustion to thermodynamic conditions}

In contrast to conventional Diesel combustion, highly diluted combustion is very sensitive to slight offsets of the initial cylinder conditions (e.g. pressure, temperature, and composition). Figs. 2 and 3 show the impact of variations in the intake manifold conditions (pressure and composition) on combustion phasings (where $\theta_{s o c}$ is the start of combustion ${ }^{2}$ and $C A_{X}$ is the crankshaft angle at which $X$ percent of the fuel has been burnt). In these experiments, the airpath parameters were changed one at a time (either the intake manifold pressure or the BGR). In practice, such airpath offsets occur during transients owing to the natural slowness of the airpath dynamics or to malfunctions such as valve clogging or aging.

\subsubsection{Impact on pollutant emissions}

Combustion phasing time-lags have detrimental effects on torque production and pollutant emissions. Fig. 4 presents results of start of injection variations on a fixed operating point on a fourcylinder HCCI Diesel engine. The only parameter that varied in this experiment was the combustion phasing; the BGR, intake manifold pressure and temperature, and injected fuel mass were kept constant at reference values obtained from look-up tables. Fig. 4 shows the obtained variations in combustion phasing and the effects on pollutants, noise and torque production. The plots clearly show that the combustion phasing has a major impact on pollutant, noise, and torque production.

\subsection{Proposed control design}

Controlling combustion has been identified as the key to control highly diluted combustion in a Diesel engine (Agrell, Angström, Eriksson, Wikander, \& Linderyd, 2003; Chang, Lavoie,

${ }^{2}$ The start of combustion is defined in theory as the beginning of combustion which is very difficult to evaluate from measurement. For experimental measurement, the $\mathrm{CA}_{01}$ is preferred here. The acquisition was not made with an industrial sensor but lab sensors which leads to very accurate measurement. 


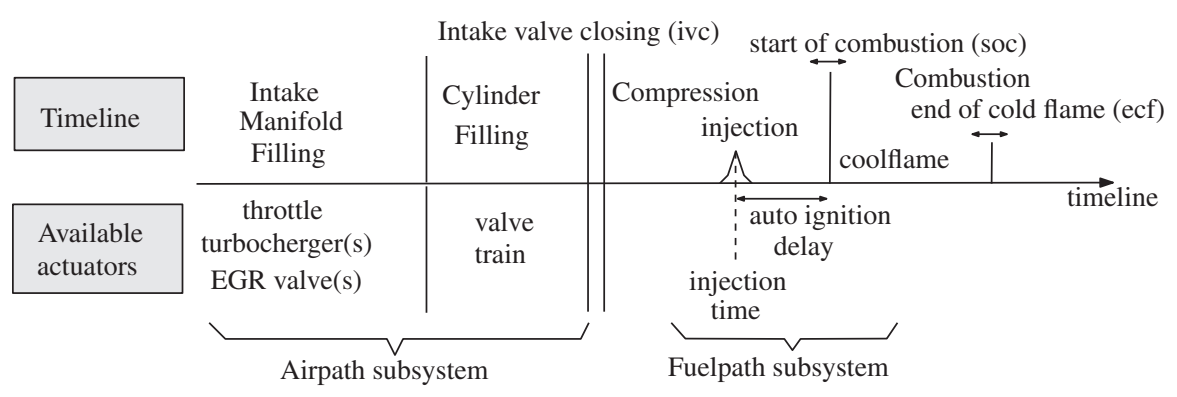

Fig. 1. Timeline of the engine cycle for highly diluted Diesel with direct injection.

a

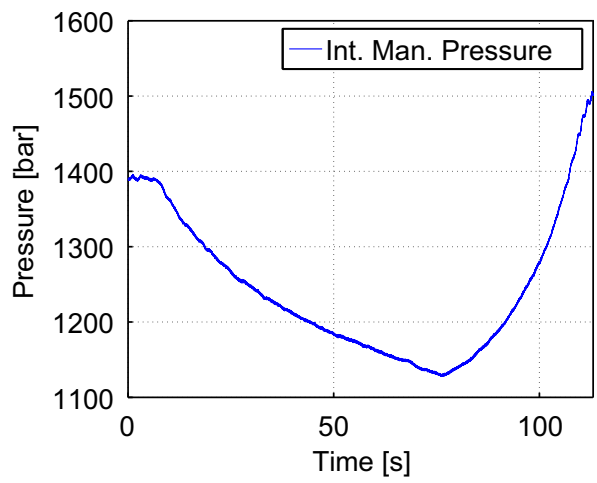

b

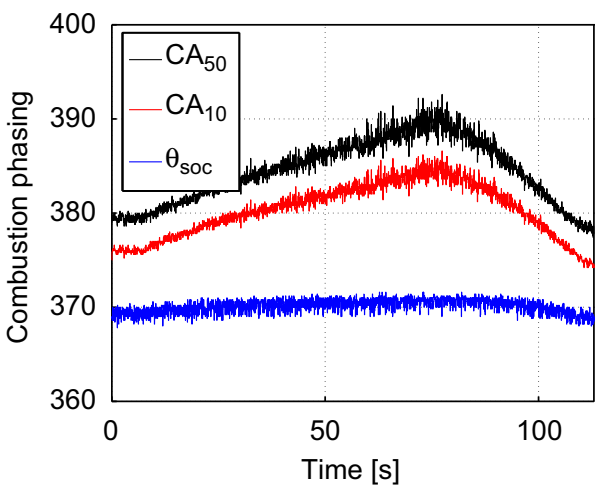

Fig. 2. Experimental results obtained for a HCCI Diesel engine at $2330 \mathrm{rpm}$. Influence of the intake manifold pressure on combustion phasings (keeping the other parameters constant). (a) Pressure, (b) combustion phasing. (For interpretation of the references to color in this figure legend, the reader is referred to the web version of this article.)

a

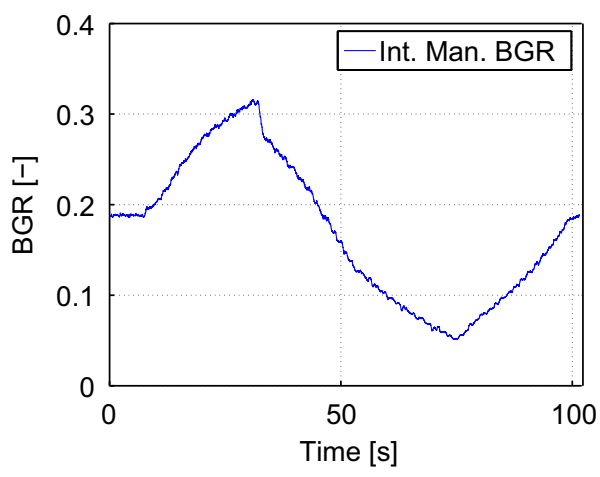

b

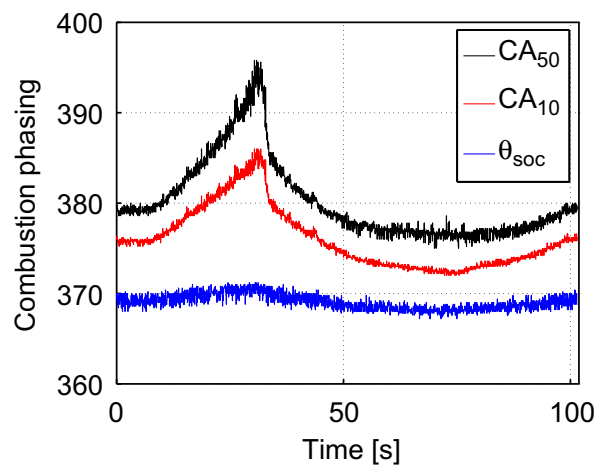

Fig. 3. Experimental results obtained for a HCCI Diesel engine at $2330 \mathrm{rpm}$ with a fixed injection pattern. Influence of the intake manifold burned gas rate on combustion phasings (keeping the other parameters constant). (a) BGR, (b) combustion phasings. (For interpretation of the references to color in this figure legend, the reader is referred to the web version of this article.)

\& Babajimopoulos, 2007; Chiang et al., 2007; Haraldsson, Tunestål, Johansson, \& Hyvonen, 2004, 2003; Olsson, Tunestål, \& Johansson, 2001). To address this issue, the approaches previously used include a variable compression ratio (Haraldsson et al., 2003), dual fuel (Olsson et al., 2001), management of the intake manifold temperature (Haraldsson et al., 2004), and a variable valve train (Agrell et al., 2003; Chang et al., 2007; Chiang et al., 2007) with high-frequency in-cylinder sensors. These solutions are costly (sensor and additional actuator). To control the combustion phasings, a solution requiring only devices available in all commercial engines, i.e. requiring no cylinder pressure sensors, is proposed in this study.

Consider a fuelpath subsystem with dynamic behavior that is inconsistent (too fast) with that of the airpath subsystem (too slow). This subsystem is controlled by the fuel injection system. The injected mass is used to produce a reference torque, and it cannot be changed without negatively affecting the performance. Therefore, only one degree of freedom for the fuelpath is a possible additional control variable. This is the injection time (start of injection) shown in the combustion timeline in Fig. 1. It can be used to inhibit combustion disturbances generated by the airpath subsystem, which can be represented as a varying intake manifold BGR, a varying intake manifold pressure and a varying intake manifold temperature.

Figs. 2 and 3 show the evolution of combustion phasings for various intake manifold pressures and different intake manifold BGR, respectively. It appears that the key variables of the combustion process are impacted differently:

1. The start of combustion is slightly delayed. The auto-ignition delay is thus impacted by thermodynamic conditions (see the evolution of the blue curves in Figs. 2(b) and 3(b)). 
a

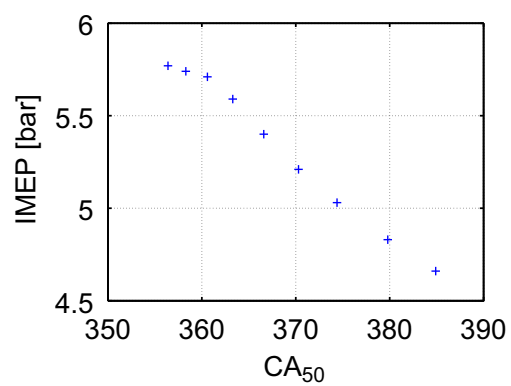

d

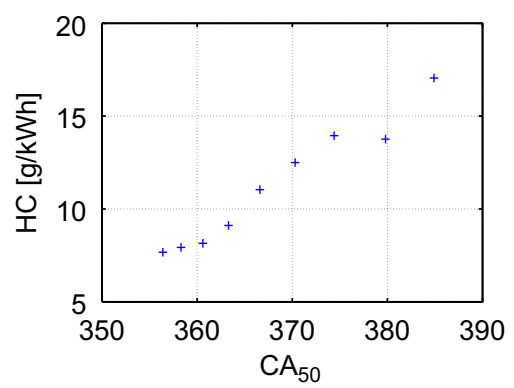

b

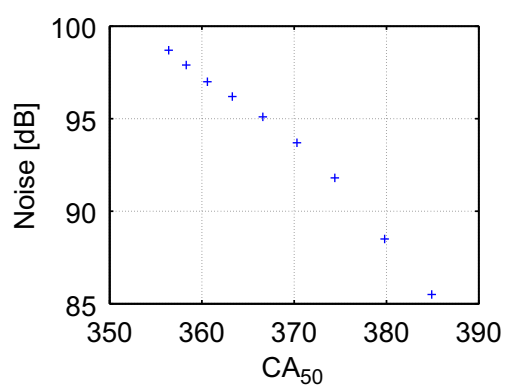

e

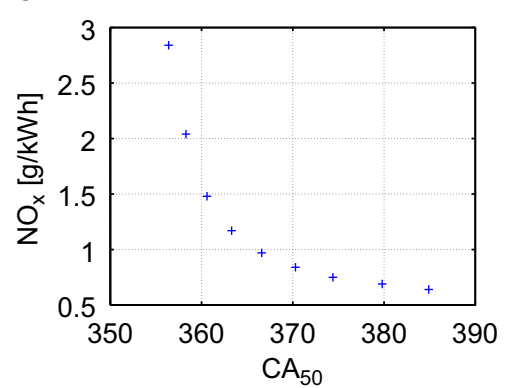

C

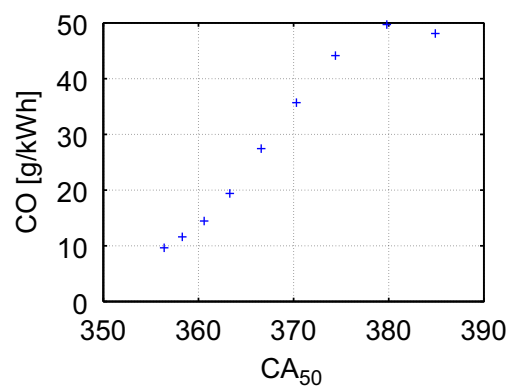

$f$

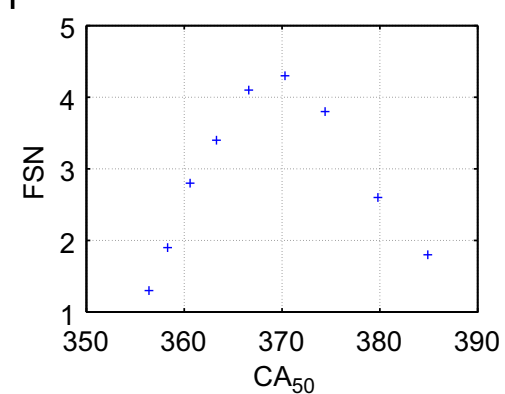

Fig. 4. Experimental results obtained with a start of injection variation on a four-cylinder HCCI Diesel engine: influence of the combustion phasing (represented by varying values of $\mathrm{CA}_{50}$ ) on engine pollutants, noise and torque production. (a) Torque, (b) noise, (c) carbon monoxide, (d) unburned hydrocarbons, (e) nitrogen oxides, (f) smoke.

2. The lag between the start of combustion $\theta_{\text {soc }}$ and $\mathrm{CA}_{10}$ varies significantly (see the relative difference between the blue and red curves in Figs. 2(b) and 3(b)).

3. The lag between $\mathrm{CA}_{10}$ and $\mathrm{CA}_{50}$ is hardly affected (see the relative difference between the red and black curves in Figs. 2(b) and 3(b)).

These observations lead to the conclusion that the cool flame and auto-ignition are the phenomena that are most sensitive to airpath-driven thermodynamic conditions, and that controlling the end of the cool flame (ecf) is sufficient to provide effective control of $\mathrm{CA}_{50}$.

Finally, cascade of ecf control onto the injection time $\theta_{\text {soi }}$ variable is proposed in this study. This implies that, instead of constant values corresponding to references, $\theta_{\text {soi }}$ has non-constant values during transients. Two particular phenomena have to be accounted for in the control law: auto-ignition and the cool flame. In the following, details about these phenomena models are discussed.

\section{Modeling the auto-ignition and the cool flame}

The two models used for the auto-ignition and cool-flame phenomena are now discussed.

\subsection{Auto-ignition modeling}

The auto-ignition duration for a fuel/air/burned gas mixture is usually modeled with a knock integral model (KIM) (Heywood, 1988; Livengood \& Wu, 1955; Swan, Shahbakhti, \& Koch, 2006). This model yields an implicit relation between $\theta_{s o i}, \theta_{s o c}$ and physical in-cylinder parameters such as $P(\theta), T(\theta)$ and $X$ (the air/ fuel ratio $\phi$ can be also considered), usually found in integral form

$\int_{\theta_{\text {soi }}}^{\theta_{\text {soc }}} \mathcal{A}^{a i}(p(\theta)) \frac{d \theta}{N_{e}}=1$,

where $\mathcal{A}^{a i}$ is an Arrhenius function and $p(\theta)=(P(\theta), T(\theta), X)^{T}$. The control strategy proposed here can be used with any (smooth) function $\mathcal{A}^{a i}$. Barba et al. (2000) adapted a phenomenological model for conventional Diesel applications:

$p(\theta)=(P(\theta), T(\theta), \phi)$,

$\mathcal{A}^{a i}(p(\theta))=c_{1} \phi^{c_{2}}\left(\frac{P(\theta)}{P_{\text {ref }}}\right)^{c_{3}} \exp \left(-\frac{T_{A}}{T(\theta)}\right)$,

where $c_{1}, c_{2}, c_{3}, P_{r e f}$, and $T_{A}$ are constant parameters. Swan et al. (2006) used the following Arrhenius function:

$p(\theta)=(P(\theta), T(\theta), X, \phi)$,

$\mathcal{A}^{a i}(p(\theta))=\frac{\phi^{x}}{\left(C_{1}+C_{2} X\right)} \exp \left(-b \frac{P(\theta)^{n}}{T(\theta)}\right)$,

where $x, C_{1}, C_{2}, b$ and $n$ are constant parameters. Lafossas, Marbaix, and Menegazzi (2007) extended the KIM to high BGR. The proposed model is thus suitable for highly diluted combustion such as $\mathrm{HCCI}$ :

$p(\theta)=(P(\theta), T(\theta), X)^{T}$,

$\mathcal{A}^{a i}(p(\theta))=\frac{A_{1}}{1+C_{1} X} P(\theta)^{n_{1}} \exp \left(-\frac{T_{1}}{T(\theta)}\right)$,

where $A_{1}, C_{1}, n_{1}$, and $T_{1}$ are constant positive parameters (see Appendix $\mathrm{B}$ for their calibration). The last model is used throughout the paper and experiments, but it should be remembered that the proposed control strategy can also be used with models (1) and (2) or any other (smooth) function $\mathcal{A}^{a i}$ using exactly the same approach.

\subsection{Cool flame modeling}

In a cool flame, combustion occurs at a very low reaction rate. Several chemical processes occur simultaneously and eventually lead to real combustion. No simple modeling of this phenomena is present in the literature. As the energy production is very low, the cool-flame duration can be represented with a KIM. Thus, as can be seen in see Appendix B, a KIM model is good enough for 
control purpose. Yet, its calibration is different to the autoinflammation model as the phenomena is different.

The main in-cylinder parameters affecting the cool-flame phenomenon are the pressure, temperature, composition (BGR), and the available fuel mass (which is the injected fuel mass, since no injection is performed during the cool flame). The proposed model is

$\int_{\theta_{\text {soc }}}^{\theta_{\text {ecf }}} \mathcal{A}^{c f}\left(p(\theta), m_{i n j}\right) \frac{d \theta}{N_{e}}=1$,

where $p(\theta)=(P(\theta), T(\theta), X)^{T}$, and $\mathcal{A}^{c f}$ is an Arrhenius function

$\mathcal{A}^{c f}\left(p(\theta), m_{i n j}\right)=\frac{A_{2}\left(m_{i n j}\right)^{X_{2}}}{1+C_{2} X} P(\theta)^{n_{2}} \exp \left(-\frac{T_{2}}{T(\theta)}\right)$,

where $A_{2}, C_{2}, n_{2}, x_{2}$, and $T_{2}$ are positive parameters (see Appendix $\mathrm{B}$ for their calibration).

\subsection{Relating knock integrals to available measurements}

The proposed models ( 3 ) and (4) are expressed in terms of incylinder thermodynamic variables $(P(\theta), T(\theta)$, and $X)$ that are not directly measured on commercial engines. Therefore, it is necessary to rewrite them in terms of other parameters.

During the compression and auto-ignition phases, no combustion occurs. The transformation can then be assumed to be isentropic (Rausen, Stefanopoulou, Kang, Eng, \& Kuo, 2004). This thermodynamic assumption is supported by the fact that, during compression, the gas temperature is much lower than it is during combustion. In short, during the compression phase, wall heating losses are neglected.

Furthermore, during the cool flame, the rate of heat released (ROHR) is low and therefore the compression can also be assumed to be isentropic. This assumption drastically simplifies the modeling, since there is no need for a cool-flame ROHR model. At the light of the results presented in Section 5, this is a reasonably valid assumption.

Thus, during auto-ignition and the cool flame, $P V^{\gamma}$ and $T V^{\gamma-1}$ are both constant. In these relations, $V$ represents the cylinder volume, which is perfectly known as a function of the crankshaft angle $\theta$. Values for intake valve closure ivc are considered as initial conditions for the isentropic transformation. These considerations yield

$\left\{\begin{array}{l}P(\theta)=P_{i v c} v_{i v c}(\theta)^{\gamma} \\ T(\theta)=T_{i v c} v_{i v c}(\theta)^{\gamma-1}\end{array} \quad\right.$ with $v_{i v c}(\theta) \triangleq \frac{V\left(\theta_{i v c}\right)}{V(\theta)}$.

Finally, in models (3) and (4), $X$ is constant and is equal to the $X_{i v c}$ value.

Substituting Eq. (5) into (3) and (4) leads to

$\mathcal{A}^{a i}(p(\theta)) \triangleq \mathcal{A}_{i v c}^{a i}\left(p_{i v c}, \theta\right)$

$\mathcal{A}^{c f}\left(p(\theta), m_{i n j}\right) \triangleq \mathcal{A}_{i v c}^{c f}\left(p_{i v c}, m_{i n j}, \theta\right) \quad$ where $p_{i v c} \triangleq\left(P_{i v c}, T_{i v c}, X_{i v c}\right)$.

In particular, the cool-flame Arrhenius function $\mathcal{A}_{i v c}^{c f}$ becomes

$\mathcal{A}_{i v c}^{c f}\left(p_{i v c}, m_{i n j}, \theta\right)=\frac{A_{2}\left(m_{i n j}\right)^{x_{2}}}{1+C_{2} X_{i v c}} P_{i v c}^{n_{2}} v_{i v c}(\theta)^{n_{2} \gamma} \exp \left(-\frac{T_{2}}{T_{i v c} v_{i v c}(\theta)^{\gamma-1}}\right)$.

Eventually, the auto-ignition and cool-flame models are thus expressed in the following form:

$\left\{\begin{array}{l}\int_{\theta_{s o i}}^{\theta_{s o c}} \mathcal{A}_{i v c}^{a i}\left(p_{i v c}, \theta\right) \frac{d \theta}{N_{e}}=1, \\ \int_{\theta_{s o c}}^{\theta_{e c}} \mathcal{A}_{i v c}^{c f}\left(p_{i v c}, m_{i n j}, \theta\right) \frac{d \theta}{N_{e}}=1 .\end{array}\right.$

The values $\left(P_{i v c}, T_{i v c}, X_{i v c}\right)$ can be directly related to the intake manifold conditions $\left(P_{\text {int }}, T_{\text {int }}, X_{\text {int }}\right)$ following classical assumptions such as pressure and composition equilibrium between the intake manifold and the cylinder at ivc (Hillion, Chauvin, Grondin, \& Petit, 2008). Finally, the intake manifold conditions $\left(P_{\text {int }}, T_{\text {int }}, X_{\text {int }}\right)$ can be inferred either from measurements (using temperature and pressure sensors in the intake manifold) or from an observer (Chauvin et al., 2007 describe a $X_{\text {int }}$ observer). The ivc parameters $\left(P_{i v c}, T_{i v c}, X_{i v c}\right)$ are then assumed to be known functions of the intake manifold conditions.

\section{Control strategy}

\subsection{Problem formulation}

At steady-state, all the $p_{i v c} \triangleq\left(P_{i v c}, T_{i v c}, X\right)$ parameters are stabilized by the airpath controller to their reference values $\left(\bar{p}_{i v c}\right)$. Furthermore, the injection timing $\theta_{\text {soi }}$ is directly set to its reference value $\left(\bar{\theta}_{s o i}\right)$ by the fuelpath controller. Reference combustion then takes place. The corresponding reference combustion phasings $\bar{\theta}_{\text {soc }}$ and $\bar{\theta}_{\text {ecf }}$ satisfy:

$\int_{\bar{\theta}_{s o i}}^{\bar{\theta}_{s o c}} \mathcal{A}_{i v c}^{a i}\left(\bar{p}_{i v c}, \theta\right) \frac{d \theta}{N_{e}}=1$,

$\int_{\bar{\theta}_{\text {soc }}}^{\bar{\theta}_{\text {ecf }}} \mathcal{A}_{i v c}^{c f}\left(\bar{p}_{i v c}, \bar{m}_{i n j}, \theta\right) \frac{d \theta}{N_{e}}=1$.

However, during transients, $\delta p \triangleq p_{i v c}-\bar{p}_{i v c} \neq 0$. If fuel is injected at reference time $\bar{\theta}_{s o i}$, then ecf differs from the value observed for reference combustion. To overcome this, the fuelpath parameters can be used. Control of the injected fuel mass $m_{i n j}$ is already dedicated to regulation of the torque output. Thus, the only degree of freedom available is the injection time. To compensate any known error $\delta p$, a corrective offset $\delta \theta_{s o i}$ is added to the injection time reference $\bar{\theta}_{\text {soi }}$ so that the actual $\theta_{\text {ecf }}$ can be equal to $\bar{\theta}_{\text {ecf }}$. This is formulated in the following problem.

Problem 1. Given $\bar{\theta}_{s o i}, \bar{p}_{i v c}, \bar{\theta}_{s o c}$, and $\bar{\theta}_{e c f}$ satisfying (8) and (9), consider $\delta p \in \mathbb{R}^{3}$. Find $\delta \theta_{s o i}$ such that

$\int_{\bar{\theta}_{s o i}+\delta \theta_{s o i}}^{\bar{\theta}_{s o c}+\delta \theta_{s o c}} \mathcal{A}_{i v c}^{a i}\left(\bar{p}_{i v c}+\delta p, \theta\right) \frac{d \theta}{N_{e}}=1$,

$\int_{\bar{\theta}_{s o c}+\delta \theta_{s o c}}^{\bar{\theta}_{e c f}} \mathcal{A}_{i v c}^{c f}\left(\bar{p}_{i v c}+\delta p, \bar{m}_{i n j}, \theta\right) \frac{d \theta}{N_{e}}=1$.

\subsection{First-order solution}

It might be difficult to find an explicit solution to Problem 1 when considering general Arrhenius functions of the form (3). A simpler approach is to look for a first-order solution. Linearizing (10) around references values $\bar{\theta}_{s o i}, \bar{p}_{i v c}$, and $\bar{\theta}_{s o c}$ yields:

$$
\begin{aligned}
& \int_{\bar{\theta}_{s o i}}^{\bar{\theta}_{s o c}} \mathcal{A}_{i v c}^{a i}\left(\bar{p}_{i v c}, \theta\right) \frac{d \theta}{N_{e}}+\int_{\bar{\theta}_{s o i}}^{\bar{\theta}_{s o c}} \frac{\partial \mathcal{A}_{i v c}^{a i}}{\partial p_{i v c}}\left(\bar{p}_{i v c}, \theta\right) \frac{d \theta}{N_{e}} \delta p+\mathcal{A}_{i v c}^{a i}\left(\bar{p}_{i v c}, \bar{\theta}_{s o i}\right) \frac{1}{N_{e}} \delta \theta_{s o i} \\
& -\mathcal{A}_{i v c}^{a i}\left(\bar{p}_{i v c}, \bar{\theta}_{s o c}\right) \frac{1}{N_{e}} \delta \theta_{s o c}=1 .
\end{aligned}
$$

Using (8) leads to

$\alpha_{s o c}^{a i} \delta \theta_{s o c}+\alpha_{s o i}^{a i} \delta \theta_{s o i}+\alpha_{p}^{a i} \delta p=0$,

where

$\alpha_{s o c}^{a i}=-\mathcal{A}_{i v c}^{a i}\left(\bar{p}_{i v c}, \bar{\theta}_{s o c}\right)$,

$\alpha_{s o i}^{a i}=\mathcal{A}_{i v c}^{a i}\left(\bar{p}_{i v c}, \bar{\theta}_{s o i}\right)$ 


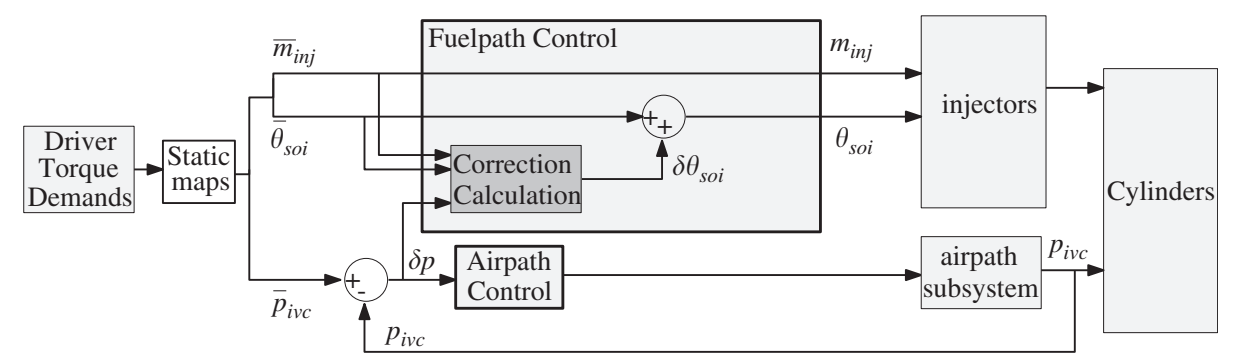

Fig. 5. Design of the proposed control strategy. The dark gray block has been added to counterbalance airpath errors $\delta p$ with an injection crankshaft angle offset. It coordinates the fuelpath and airpath controllers.

$\alpha_{p}^{a i}=\int_{\bar{\theta}_{s o i}}^{\bar{\theta}_{s o c}} \frac{\partial \mathcal{A}_{i v c}^{a i}}{\partial p_{i v c}}\left(\bar{p}_{i v c}, \theta\right) d \theta$.

Similarly, linearizing (11) around reference values $\bar{\theta}_{s o c}, \bar{p}_{i v c}$, and $\bar{\theta}_{\text {ecf }}$ gives

$\alpha_{s o c}^{c f} \delta \theta_{s o c}+\alpha_{e c f}^{c f} \delta \theta_{e c f}+\alpha_{p}^{c f} \delta p=0$,

where

$\alpha_{s o c}^{c f}=\mathcal{A}_{i v c}^{c f}\left(\bar{p}_{i v c}, \bar{\theta}_{s o c}, \bar{m}_{i n j}\right)$

$\alpha_{e c f}^{c f}=-\mathcal{A}_{i v c}^{c f}\left(\bar{p}_{i v c}, \bar{\theta}_{e c f}, \bar{m}_{i n j}\right)$

$\alpha_{p}^{c f}=\int_{\bar{\theta}_{s o c}}^{\bar{\theta}_{e c f}} \frac{\partial \mathcal{A}_{i v c}^{c f}}{\partial p_{i v c}}\left(\bar{p}_{i v c}, \bar{m}_{i n j}, \theta\right) d \theta$.

Eliminating $\delta \theta_{s o c}$ in (12) and (13) yields the desired correction:

$\delta \theta_{s o i}=\frac{\alpha_{s o c}^{a i} \alpha_{p}^{c f}-\alpha_{s o c}^{c f} \alpha_{p}^{a i}}{\alpha_{s o c}^{c f} \alpha_{s o i}^{a i}} \delta p$,

which is a solution (of first order, i.e. for "small" values of $\delta p^{3}$ ) of Problem 1.

\section{Implementation}

In practice, the correction determined in the previous section is easily computable, since all parameters $\alpha$ depend on known values $p_{i v c}$ (Section 2.3), mapped values $\left(\bar{p}_{i v c}, \bar{\theta}_{s o i}\right)$ or calibrated models $\left(\mathcal{A}^{a i}, \mathcal{A}^{c f}\right)$. For application, the terms $\alpha_{p}^{a i}$ and $\alpha_{p}^{c f}$ can be simplified using actual expressions for the functions $\mathcal{A}^{a i}$ and $\mathcal{A}^{c f}$ (Hillion, Chauvin, \& Petit, 2008).

\subsection{Controller design}

The general control scheme of a Diesel engine is presented in Fig. 5. It includes the strategy proposed to control the ecf. This new strategy is in the "correction calculation", which implements Eq. (14). In this set-up, the injection crankshaft angle $\theta_{\text {soi }}$ is not simply set to its reference value $\bar{\theta}_{\text {soi }}$, but is corrected according to the airpath errors $\delta p$. In this manner, the fuelpath is coordinated with the airpath dynamics.

It is very important to note that

- No sensors or actuators have been added to the control scheme. The proposed controller uses only sensors and actuators that are commonly available.

\footnotetext{
${ }^{3}$ From a mathematical point of view it is stated that the proposed solution is the best for "small" errors $\delta p$ by definition of the first-order approximation. One cannot define explicitly what is the domain of definition of "small". However, one can see on experimental results that the "small" values are good enough for control purpose.
}

- The controller does not affect the airpath controller. The proposed controller only counterbalances airpath regulation errors by a cascade onto the fuelpath controller.

\subsection{Real-time computation}

The controller (14) contains several " $\alpha$ " parameters. Their practical derivations are now detailed.

- $\left(\alpha_{s o c}^{a i}, \alpha_{s o i}^{a i}, \alpha_{s o c}^{c f}\right)$ are values of the well-known functions $\mathcal{A}^{a i}$ and $\mathcal{A}^{c f}$. Computation of these parameters is fast and simple.

- $\left(\alpha_{p}^{a i}, \alpha_{p}^{a i}\right)$ are integrals over time of the functions $\mathcal{A}^{a i}$ and $\mathcal{A}^{c f}$. Computation of such integrals takes time that is incompatible with real-time requirements. Thus, besides analytical simplification of the integrals due to the particular form of the KIM model (Hillion, Chauvin, Grondin et al., 2008), two alternative methods can be considered to reduce the computation time.

$\circ$ In the first method, the integrands of $\left(\alpha_{p}^{a i}, \alpha_{p}^{a i}\right)$ are approximated by polynomial functions for simplicity. Straightforward quadrature is then possible.

$\circ$ In a second approach, correction is considered in the form of a ratio of parameters $\left(\alpha_{p}^{a i}, \alpha_{p}^{a i}\right)$. These parameters depend only on the setpoint values for the airpath and fuelpath parameters, which are mapped as functions of the engine speed and the driver's torque demand. Thus, the lumped parameter $\Lambda=\left(\alpha_{s o c}^{a i} \alpha_{p}^{c f}-\alpha_{s o c}^{c f} \alpha_{p}^{a i}\right) / \alpha_{s o c}^{c f} \alpha_{s o i}^{a i}$ in Eq. (15) can be mapped as a function of the engine speed and the driver's torque demand. Finally, the correction is simply written as

$\delta \theta_{\text {soi }}=\Lambda\left(N_{e}, \bar{T}_{q}\right) \cdot \delta p$.

The map $\Lambda$ (actually one map for each airpath parameter to be compensated) is computed offline and has to be modified every time an airpath or fuelpath parameter setpoint is changed. Although requiring substantial offline computation effort, computation of the correction is then straightforward.

The first solution is best suited for development phases of engine control, whereas the second can be directly implemented in commercial engine control units when calibration maps of the airpath and fuelpath setpoints are known.

To obtain the results presented below, the first method was used (using fourth-order polynomials) owing to the frequent updates of the fuelpath and airpath look-up tables for this prototype engine. The controller was integrated in the complete IFP energie nouvelles engine control system developed with Matlab/Simulink. Real Time Workshop (RTW) and XPC target toolboxes are used for real-time code generation. The execution time for the proposed controller is approximately $20 \mu \mathrm{s}$ on a 4.8-GHz target. 


\section{Experimental results on a test bench: control of the combustion}

\subsection{Experimental set-up}

All experimental results presented here were obtained for a four-cylinder direct injection Diesel engine running in $\mathrm{HCCl}$ combustion mode (Fig. 6). The specifications are listed in Table 1 . The engine is an upgrade of a turbocharged multicylinder commercial engine. A low-pressure EGR circuit is used that extracts hot burned gases downstream of the turbine and introduces them upstream of the compressor. A valve allows the EGR rate to be controlled. Finally, both the air and the EGR circuits include a cooler to keep the intake manifold temperature at approximately $330 \mathrm{~K}$.

The proposed experimental results reflect only the adaptation of the fuelpath to pressure and BGR regulation errors. However, the intake manifold temperature also affects the combustion process. Variation of ambient temperature, EGR cooling efficiency or the simultaneous use of high-pressure and low-pressure EGR strongly influence the temperature. Unfortunately, it is very difficult to get a relevant and fast measure of the intake manifold. The sensor is very slow, and does not represent well the temperature of the gas aspirated in the cylinder. Therefore, no correction with respect to temperature error was presented. However, as presented, the approach can be extended to accommodate the intake temperature variations because the intake manifold temperature can be included in the $p_{i v c}$ parameters.

The intake pressure is directly measure through a sensor. On the contrary, BGR cannot be easily measured. However, a BGR observer was developed in Chauvin, Corde, Vigild, Petit, and Rouchon (2006) and Chauvin, Corde, Petit, and Rouchon (2008) which show good results both in steady-state and in transient.

\subsection{Experimental results}

Figs. 7-9 show the experimental results obtained on the test bench for three torque variations at constant engine speed. For comparison, the plots show the same trajectory with (blue lines) and without (red lines) the proposed correction. For all three scenarios, the torque trajectory is shown in part (a). As mentioned in Section 1.1, the airpath control regulates the intake manifold pressure and BGR around their reference values to meet the torque demand (parts (b) and (c)). Non-instantaneous tracking of the airpath reference values induces the new fuelpath controller to correct the reference value for the injection crankshaft angle (part (d)). The injection crankshaft angle sent to the injectors is then different from its reference value. The influence of the proposed combustion control on engine noise is shown in part (e) of the figures and the evolution of the middle of the combustion process in part (f).

\subsubsection{Increasing torque trajectory (tip-ins)}

Fig. 7 shows an increasing torque trajectory at a constant engine speed of $1500 \mathrm{rpm}$. During these transients, without any particular combustion control, combustion is drastically delayed (see the second and third transients in Fig. 7(f)). In response, the proposed controller modifies the start of injection to bring the combustion forward. In fact, the correction seems to filter the start of injection reference to compensate for the airpath dynamics. The result is clear in Fig. 7(f). Without the proposed strategy, the middle of combustion is delayed due to the excess of BGR that leads to a delayed start of combustion. With the proposed strategy, the middle of the combustion process closely follows the corresponding reference steps and the large overshoots have disappeared. Improvements in engine noise are also evident in Fig. 7(e), with noise transients smoothed out. This results in significant improvements in acoustic comfort.

\subsubsection{Decreasing torque trajectory (tip-outs)}

Fig. 8 shows a decreasing torque trajectory at a constant engine speed of $1500 \mathrm{rpm}$. During these transients, without any particular combustion control, combustion is brought forward (see transients in Fig. 8(f)) due to a lack of BGR and of pressure. In response, the proposed controller delays the injection to delay the

Table 1

Diesel engine set-up.

\begin{tabular}{ll}
\hline Bore $\times$ stroke & $87.0 \times 92.0 \mathrm{~mm}$ \\
Number of cylinders & 4 \\
Compression ratio & $14: 1$ \\
Displacement & 2.21 \\
Injection device & Solenoid \\
Maximum injection pressure & $1600 \mathrm{bar}$ \\
Piston bowl design & $\mathrm{NADI}^{\mathrm{TM}}$ (Walter \& Gatellier, 2003) \\
Intake valve closure & $\theta_{i v c}=232^{\circ}$ \\
& $\left(360^{\circ}\right.$ is top dead center $)$
\end{tabular}

LP EGR valve LP EGR Cooler

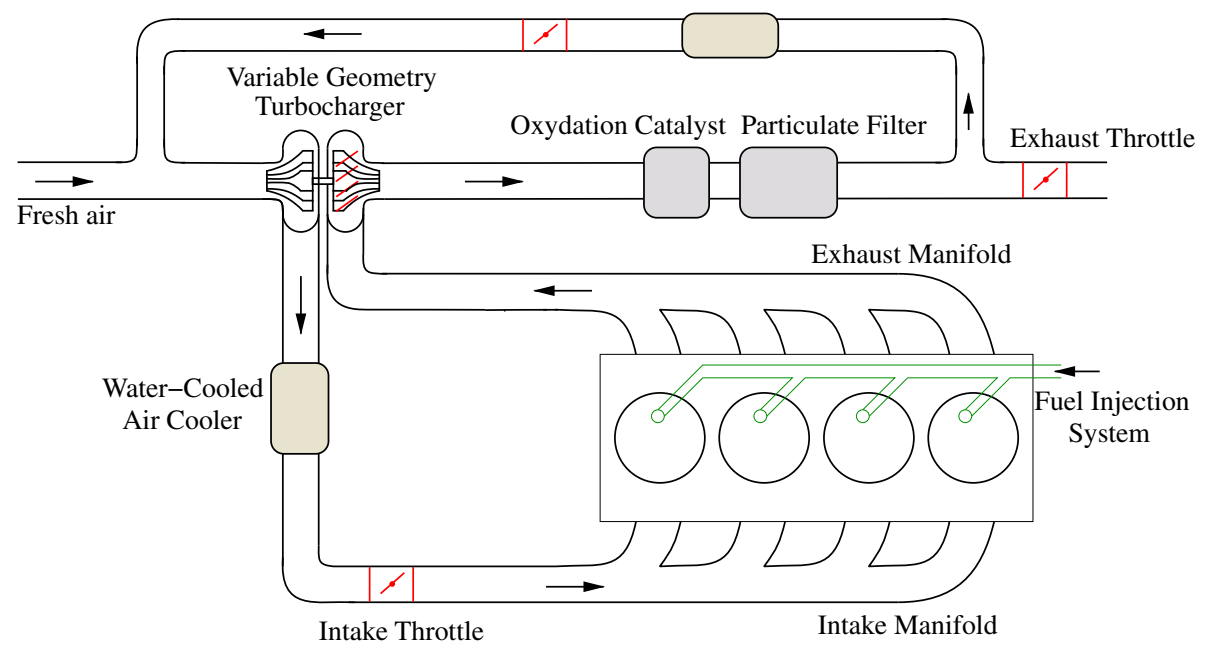

Fig. 6. Four-cylinder HCCI Diesel engine with direct injection, low-pressure EGR recirculation and a turbocharger. High BGR values are used to dilute the mixture before combustion. 
a

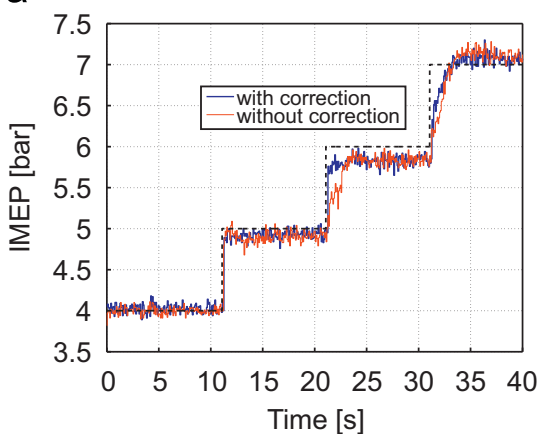

d

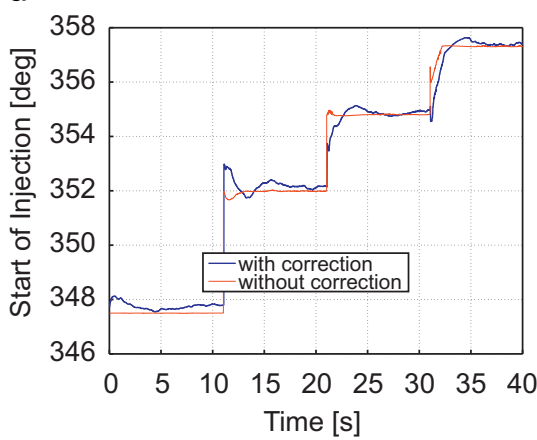

b

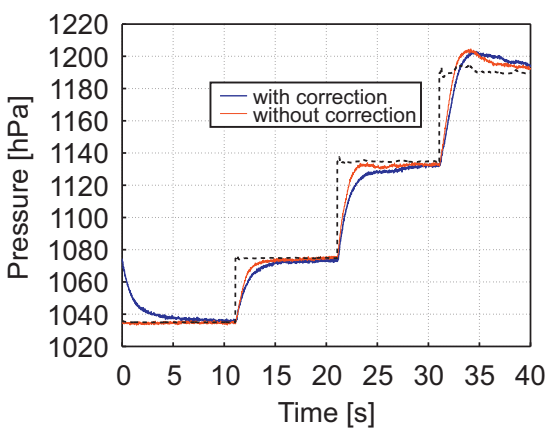

e

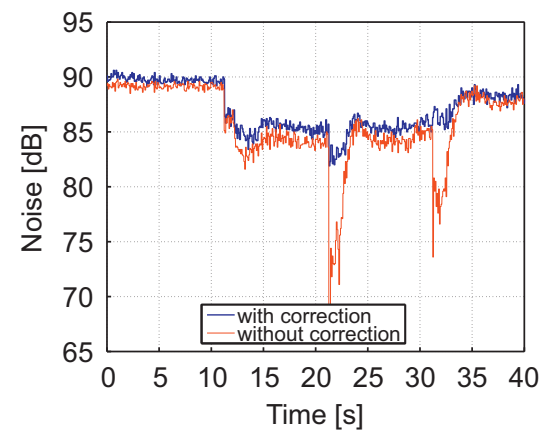

C

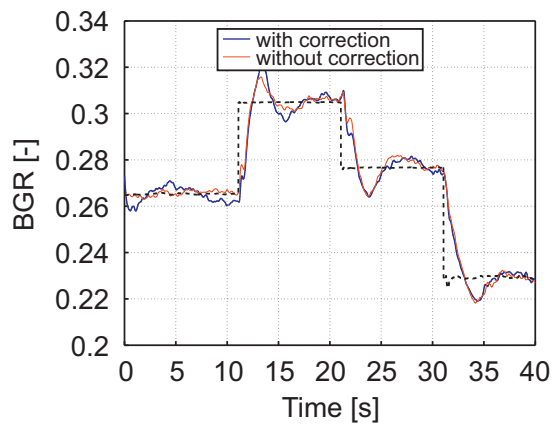

$\mathrm{f}$

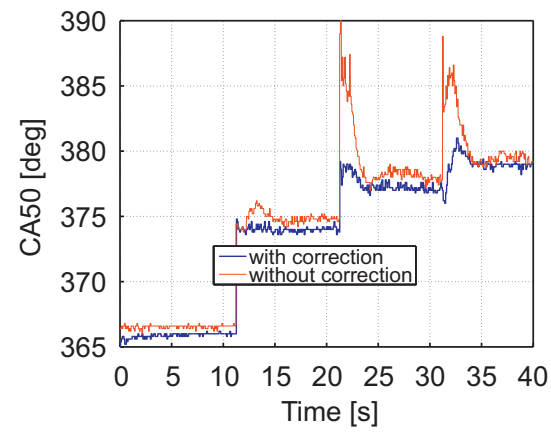

Fig. 7. Test bench results for a four-cylinder HCCI engine with direct injection for increasing torque demand at a constant speed of 1500 rpm with and without the proposed control strategy. (a) Torque, (b) intake manifold pressure, (c) intake manifold BGR, (d) injection crankshaft angle, (e) noise, (f) Ca 50 . (For interpretation of the references to color in this figure legend, the reader is referred to the web version of this article.)

a

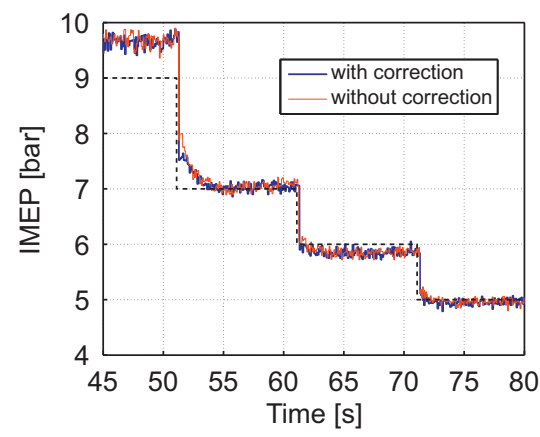

d

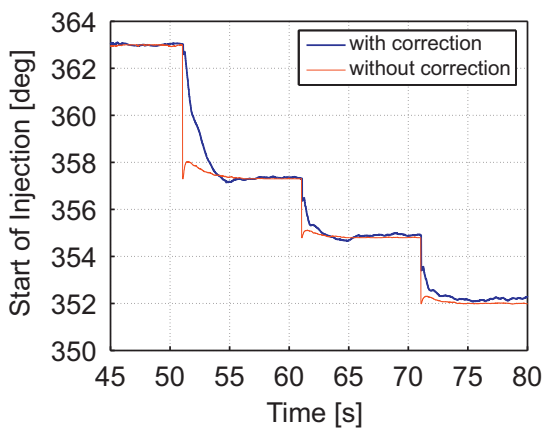

b

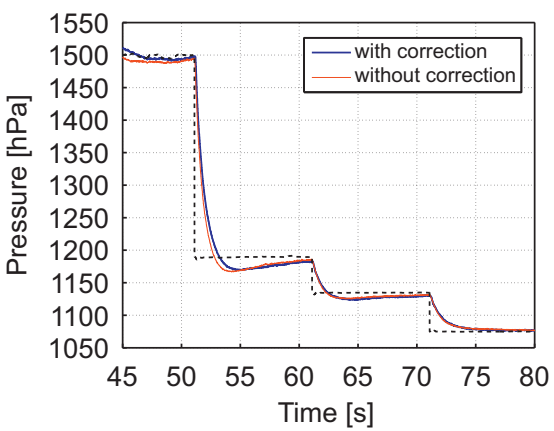

e

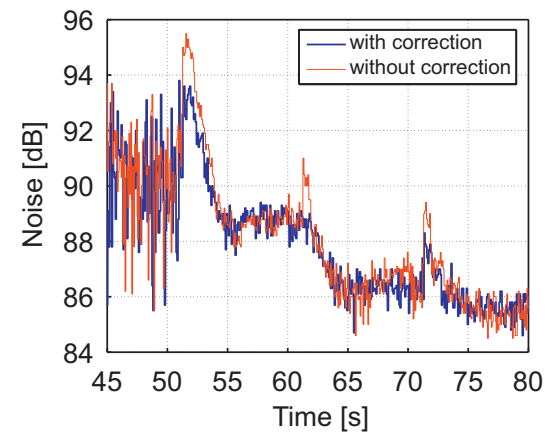

C

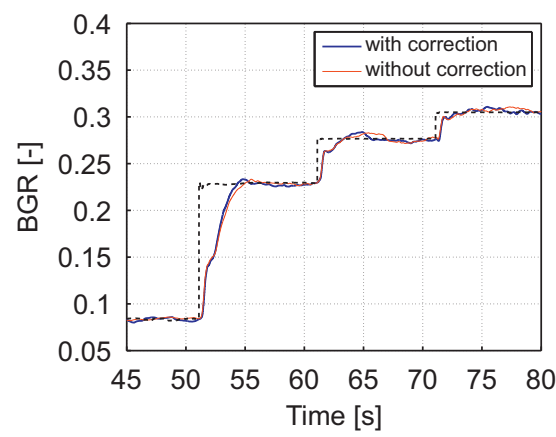

f

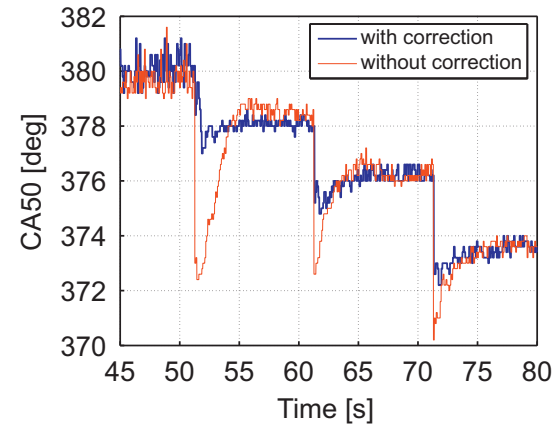

Fig. 8. Test bench results for a four-cylinder $\mathrm{HCCI}$ engine with direct injection for decreasing torque demand at a constant speed of 1500 rpm with and without the proposed control strategy. (a) Torque, (b) intake manifold pressure, (c) Intake manifold BGR, (d) injection crankshaft angle, (e) noise, (f) Ca ${ }_{50}$. (For interpretation of the references to color in this figure legend, the reader is referred to the web version of this article.)

whole combustion process. Undershoots of the middle of the combustion $\left(\mathrm{CA}_{50}\right)$ have disappeared (Fig. 8(f)). Noise overshoots during transients, which are very unpleasant for car passengers, have also been reduced (gain of almost $2 \mathrm{~dB}$ ).

\subsubsection{Results for various engine speeds}

Similar results were obtained at different speeds. Fig. 9 shows the torque demand trajectory at a constant engine speed of $2000 \mathrm{rpm}$. Again, improvements due to the proposed controller 
a

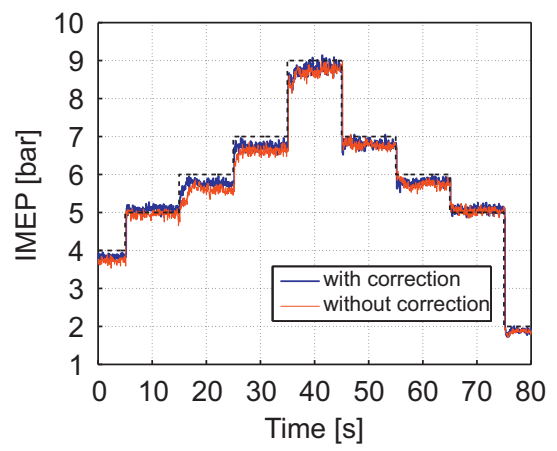

d

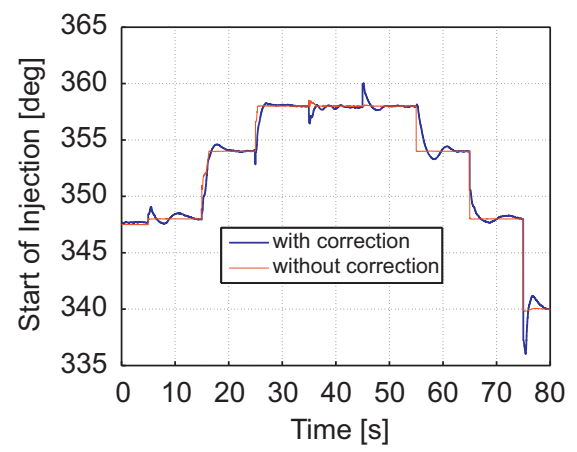

b

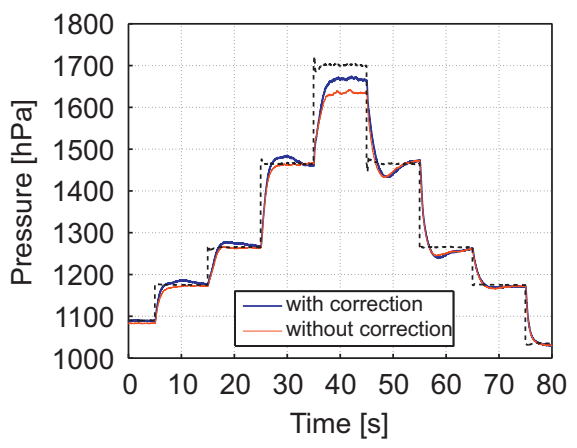

e

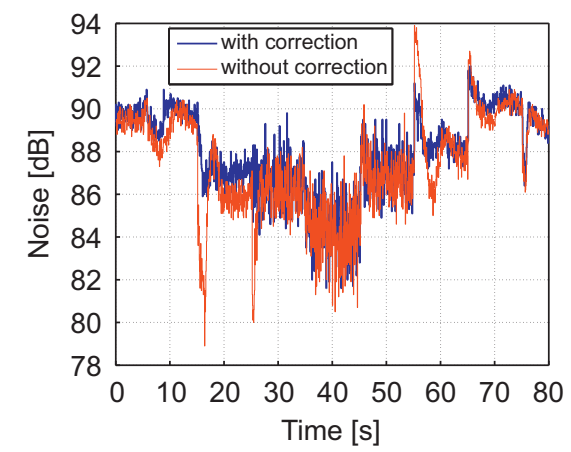

C

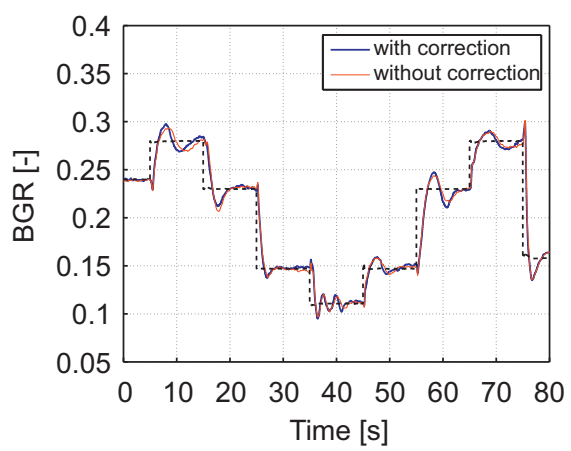

f

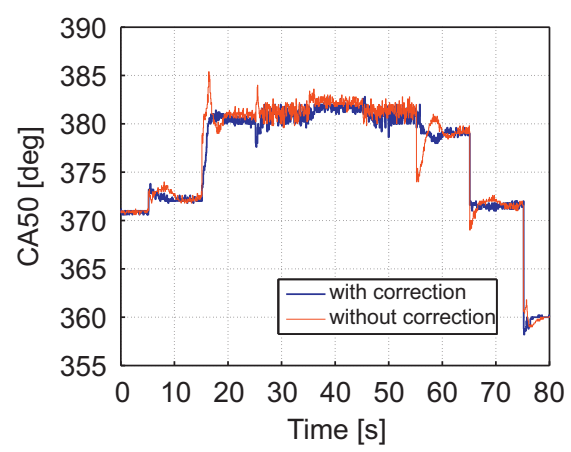

Fig. 9. Test bench results for a four-cylinder HCCI engine with direct injection for increasing and then decreasing torque demand at a constant speed of 2000 rpm with and without the proposed control strategy. (a) Torque, (b) intake manifold pressure, (c) intake manifold BGR, (d) injection crankshaft angle, (e) noise, (f) Ca50. (For interpretation of the references to color in this figure legend, the reader is referred to the web version of this article.)

are evident in the middle of the combustion variations during transients.

\subsection{Conclusions from the test bench results}

The results presented clearly prove that the strategy proposed in Section 3.2, and implementation described in Section 5 provides a solution to the control Problem 1. In spite of airpath regulation errors, such as slow transient dynamics or hardware malfunctions, the combustion midpoint occurs at the reference timing. Interestingly, the proposed linear combustion control has another property at steady-state. Since the airpath controller regulates the airpath values, the airpath error vanishes at steady-state, just as the start of injection correction. Combustion thus exactly corresponds to the reference combustion at steadystate (defined by the optimal trade-off).

The timings for auto-ignition and the cool flame are the most sensitive to airpath regulation errors. As observed from the test bench results, controlling the end of the cool flame provides good control of the whole combustion process.

\section{Vehicular results: pollutant emissions and noise}

\subsection{Experimental set-up}

The experimental results in Section 1 demonstrate that control of the combustion phasing is key to management of low-temperature combustion. Sections 2 and 3 describe a technical solution without any hardware upgrade that uses injection timing to control the end of the cool-flame phenomenon. Experimental results presented in Section 5 show that this combustion timing is a relevant approach for control of the whole combustion process since it provides accurate $\mathrm{CA}_{50}$ control. Finally, the last step of this study provides an insight into the impact of the proposed strategy on pollutant emissions and engine noise.

To obtain estimates of the emissions and noise produced under real representative driving conditions, experiments were conducted on board a vehicle equipped with high-frequency sensors to capture data during sharp transients. To highlight the benefits of the proposed strategy, a challenging part of the new European driving cycle (NEDC) was chosen. This consists of one urban driving cycle (ECE) followed by an extra-urban driving cycle (EUDC). The vehicle used was a demonstration car developed at IFP (Magand et al., 2008) that is equipped with a HCCI engine that differs from the engine described in Section 5.1 in only two respects:

- The EGR is a high-pressure circuit. Interestingly, this technological change is treated in a straightforward manner in the control scheme (which is independent of the nature of the EGR source; Section 4.1). No particular tuning is required.

- To reduce engine noise, pilot injection is added to some operating points. This consists of at most $4 \%$ of the total mass injected and is injected at a crankshaft angle of approximately $20^{\circ}$ before the main injection.

This pilot injection was not taken into account in the modeling in Section 2. However, for simplicity, the following assumptions are made to allow:

- Since the mass of the pilot injection is almost negligible compared to that of the main injection, the correction developed in Section 3.2 has been applied to the main injection 
a

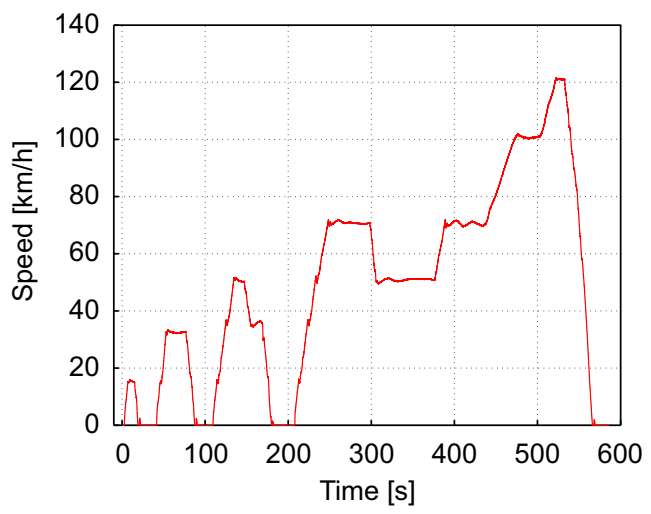

b

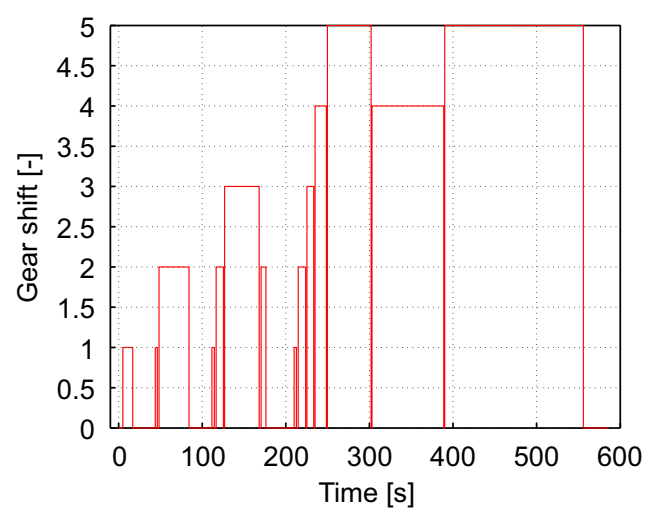

Fig. 10. Vehicle speed and gear shift results for a four-cylinder HCCI vehicle with direct injection during a normalized ECE (0-200 s) cycle and an EUDC (200-600 s) cycle. (a) Vehicle speed, (b) gear shift.

a

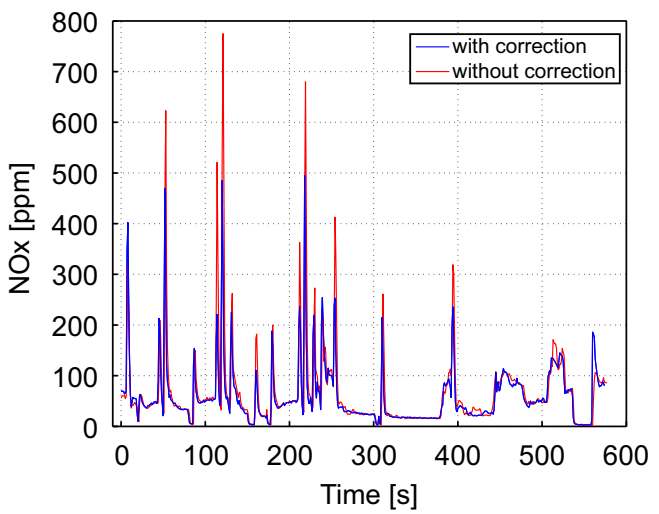

b

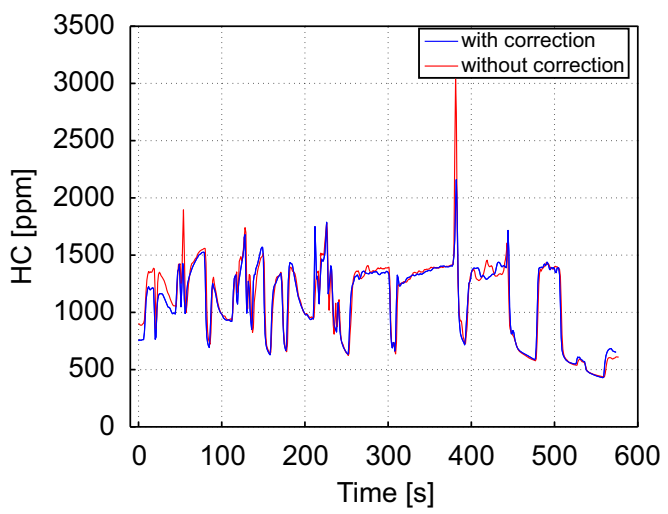

Fig. 11. Vehicle results for a four-cylinder HCCI Diesel engine with direct injection. $\mathrm{NO}_{x}$ and $\mathrm{HC}$ emissions during a normalized ECE (0-200 s) cycle and an EUDC (200-600 s) cycle. (a) $\mathrm{NO}_{x}$, (b) $\mathrm{HC}$.

without any particular modification (as in the test bench results in Section 5).

- Since the pilot injection occurs at a specific crankshaft angle before the main injection, the pilot injection is delayed or advanced by the same amount as the main injection.

In summary, for operating points equipped with pilot injection, the correction shifts the whole injection pattern, whereas for operating points without pilot injection the correction is classically applied to the main injection timing only.

Results are presented in Figs. 10-12. Fig. 10 gives an overview of the vehicle speed and gear shift during the driving cycle. Fig. 12 provides more detailed views of the previous results during a representative tip-in.

\subsection{Vehicle results for the whole cycle}

Fig. 11(a) and (b) shows nitrogen oxide $\left(\mathrm{NO}_{x}\right)$ and unburned hydrocarbon (HC) emissions obtained during this cycle. Overall, $\mathrm{NO}_{x}$ peaks are drastically reduced (by a factor of two). The HC peaks are also reduced, albeit to a lesser extent. It is evident that HC transients are hardly visible in both cases, except at $t=375 \mathrm{~s}$, which is addressed in the next section.

\subsection{Vehicle results during a tip-in}

The results for a tip-in are shown in Fig. 12. On two occasions the torque produced is problematic. At $t=375 \mathrm{~s}$ a misfire occurs.
Later, a smaller decrease can be observed at $t=377 \mathrm{~s}$. These are evident in Fig. 12(b) and correspond to the combustion phasing shifts depicted in Fig. 12(f). In both cases, the combustion is so delayed that the torque produced drastically decreases and huge noise variations occur (Fig. 12(d)), thus negatively affecting driveability and acoustic comfort. The first misfire is also responsible for the speed variation at the beginning of the tip-in in Fig. 12(a), and, most importantly, for the overwhelming HC production detected at $t=380 \mathrm{~s}$ in Fig. 12(c) (after a lag due to flow through the exhaust line and the analysis process). Using soi correction computed by the proposed method, as observed in Fig. 12(e), all these issues are resolved: transients in the combustion phasing are controlled, the misfires disappear, HC production is substantially reduced, and the noise level remains close to its steady-state value.

\section{Conclusion}

An improvement for fuelpath control of a highly diluted Diesel engine has been presented. Instead of directly setting the injection crankshaft angle to its reference value, the proposed controller synchronizes the fuelpath to the airpath. In particular, this makes the combustion robust to airpath regulation errors (during transients or malfunctions). This controller is mainly based on the linearization of an auto-ignition delay model (KIM) and a coolflame model. Provided an estimate of in-cylinder conditions at ivc 
a

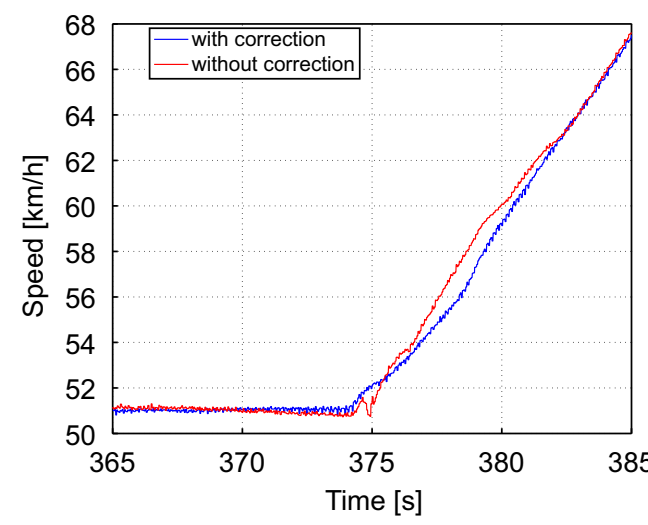

C

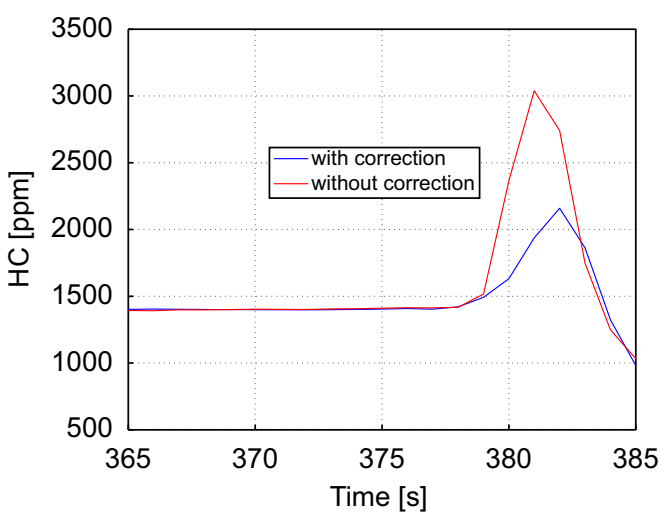

e

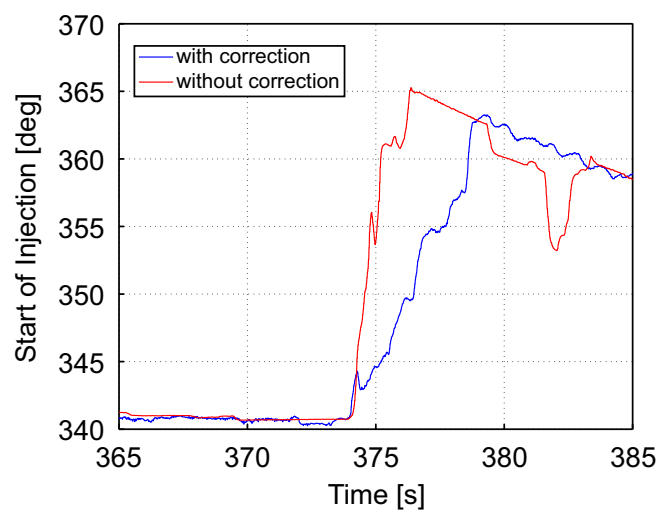

b

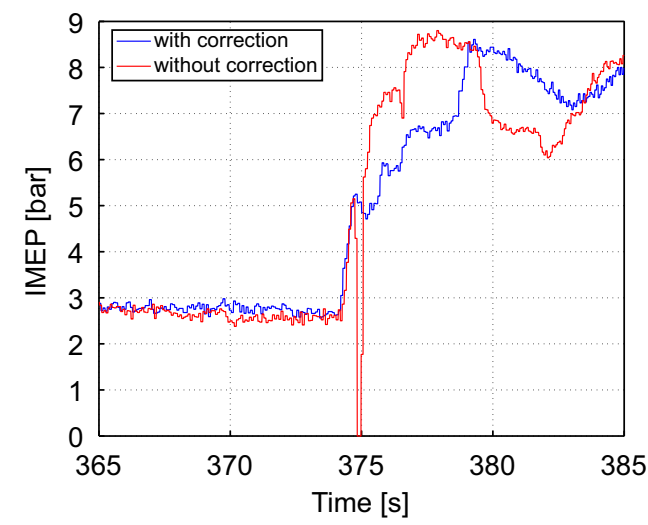

d

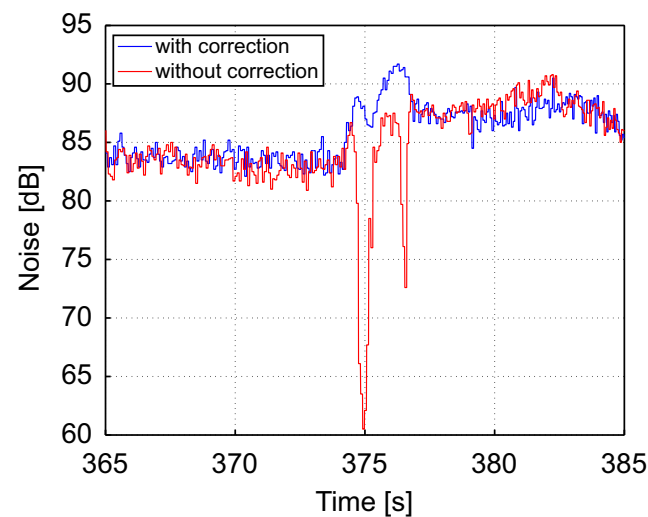

f

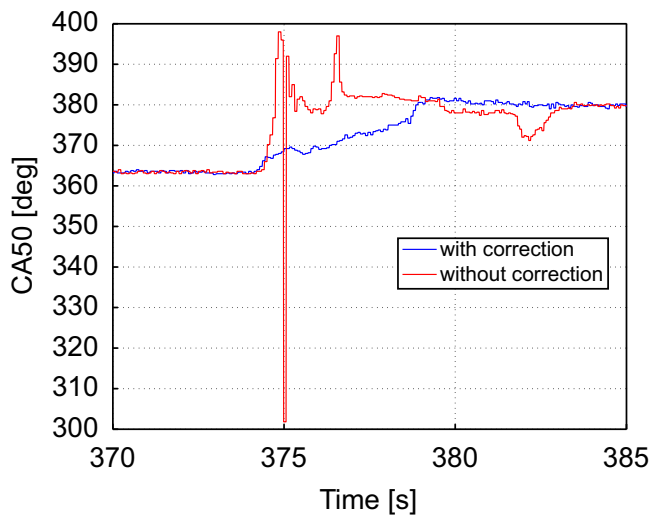

Fig. 12. Vehicle results for a four-cylinder HCCI Diesel engine with direct injection. Effect of correction on a tip-in at $50 \mathrm{~km} / \mathrm{h}$. (a) Vehicle speed, (b) Torque, (c) Hydrocarbons, (d) Noise, (e) Start of injection, (f) Ca $\mathrm{Ca}_{50}$.

is known (in this study, the conditions are inferred from the intake manifold signals), this method is very general.

- It is independent of the airpath structure. It can be applied to engines with external or internal gas recirculation, and to naturally aspirated engines, throttled engines and/or those with turbochargers.

- The method does not need any hardware upgrade. In particular, no additional in-cylinder sensor is needed.

- The proposed control strategy reduces the impact of pollutant emissions in transient and leads pollutant emissions closer to the values observed at steady-state.

The experimental results highlight the relevance of this new approach. Auto-ignition and the cool flame are critical phenomena for the whole combustion process. Controlling the end of the cool flame leads to an improvement in combustion stability. During transients, the combustion phasing is closely controlled, which in turn improves the torque response and smoothes out noise transients. It is thus reasonable to expect better driveability and acoustic comfort. Finally, the vehicular results demonstrate that combustion phasing control is beneficial in terms of pollutant emissions. It reduces $\mathrm{NO}_{x}$ peaks during transients by a factor of almost two and prevents $\mathrm{HC}$ peaks by stabilizing the combustion phasings.

The results obtained for a Diesel engine with a monopulse injection strategy (and rapidly extended to a pilot-main injection strategy) are very encouraging. Ongoing research is now focusing on generalizing the model-based generation of the correction to more general multi-pulse Diesel engines. 


\section{Acknowledgment}

The authors would like to gratefully thank Gilles Corde for his scientific support.

\section{Appendix A. Nomenclature and acronyms}

A complete nomenclature and acronyms is given in Tables A1 and $\mathrm{A} 2$.

\section{Appendix B. Calibration of the models}

In Eqs. (3) and (4) the parameter sets $\left(A_{1}, C_{1}, n_{1}, T_{1}\right)$ and $\left(A_{2}, C_{2}, n_{2}, x_{2}, T_{2}\right)$ can be obtained using a classical optimization process (Heywood, 1988). To calibrate both, 100 working points were selected corresponding to representative variations of pressure, temperature, BGR, and injection timing for four different engine speeds (1000, 1500, 2000 and $2500 \mathrm{rpm}$ ).

Classical combustion analysis was carried out for each working point using cylinder pressure histories (currently available for the development engine test bed). This analysis allows determination of the actual start of combustion and the actual end of the cool flame. These results constitute the reference database.

The optimization process was then carried out independently on the auto-ignition model and the cool-flame model. The global accuracy of the models is depicted in Fig. B1, in which model

Table A1

Nomenclature.

\begin{tabular}{lll}
\hline Symbol & Quantity & Unit \\
\hline$\theta$ & Crankshaft angle & $\circ$ \\
$V$ & Cylinder volume & $\mathrm{m}^{3}$ \\
$P(\theta)$ & Cylinder pressure & $\mathrm{Pa}$ \\
$T(\theta)$ & Cylinder temperature & $\mathrm{K}$ \\
$X$ & In-cylinder burned gas rate (BGR) & - \\
$V_{i v c}$ & In-cylinder volume at ivc & $\mathrm{m}^{3}$ \\
$P_{i v c}$ & Cylinder pressure at $i v c$ & $\mathrm{~Pa}$ \\
$T_{i v c}$ & Cylinder temperature at $i v c$ & $\mathrm{~K}$ \\
$\phi$ & Air/fuel ratio & - \\
$\theta_{s o i}$ & Injection crankshaft angle & $\circ$ \\
$\theta_{s o c}$ & Start of combustion crankshaft angle & $\circ$ \\
$m_{i n j}$ & Injected fuel mass & $\mathrm{mg}$ \\
$\gamma$ & Ratio of specific heat & - \\
$T_{q}$ & Torque & $\mathrm{N} \mathrm{m}$ \\
$N_{e}$ & Engine speed & $\mathrm{rpm}$ \\
\hline
\end{tabular}

Table A2

Acronyms.

\begin{tabular}{ll}
\hline HCCI & $\begin{array}{l}\text { Homogeneous charge-compression } \\
\text { ignition }\end{array}$ \\
IMEP & Indicated mean effective pressure \\
CAX & X\% of fuel mass burnt \\
ivc & Intake valve closure \\
soi & Start of injection \\
soc & Start of combustion \\
ecf & End of cool flame \\
EGR & Exhaust Gas Recirculation \\
VVA & Variable valve actuation \\
KIM & Knock integral model \\
BGR & Burned gas rate \\
TDC & Top dead center \\
NEDC & New European driving cycle \\
ECE & Urban driving cycle \\
EUDC & Extra-urban driving cycle \\
NO & Nitrogen oxides \\
HC & Unburned hydrocarbons \\
\hline
\end{tabular}

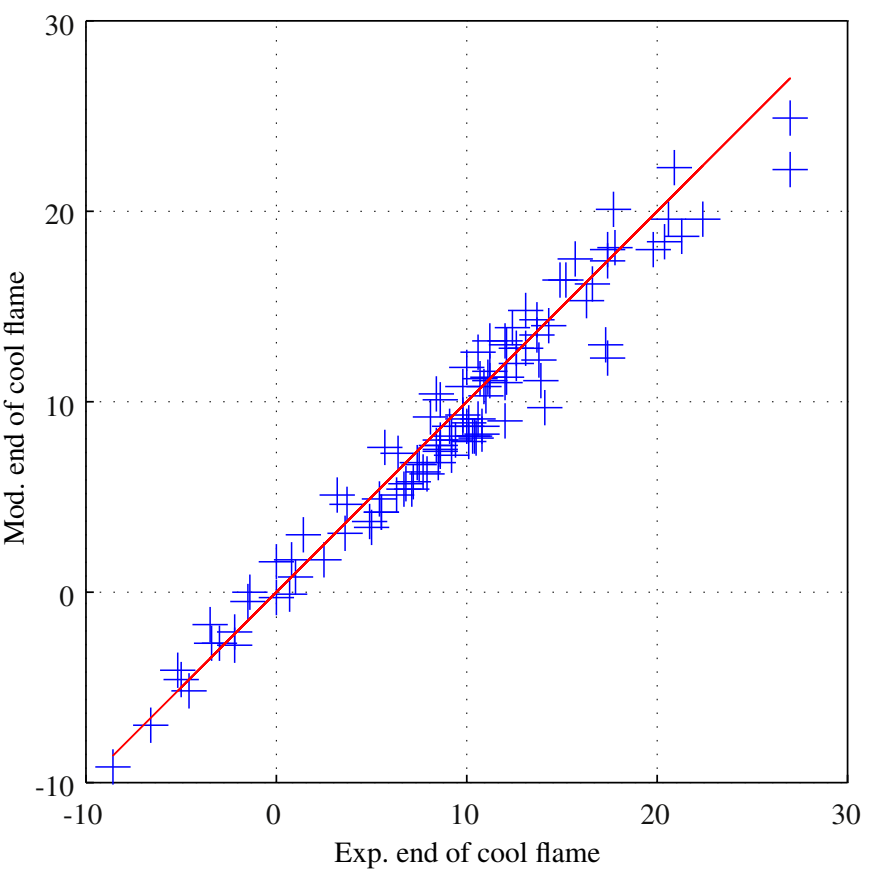

Fig. B1. Calibration of the cool-flame model: modeled vs. experimental ecf.

predictions are compared to the reference database. There is relatively good agreement between the experimental and model data.

\section{References}

Agrell, F., Angström, H.-E., Eriksson, B., Wikander, J., \& Linderyd, J. (2003). Transient control of HCCI through combined intake and exhaust valve actuation. In Proceedings of the society of automotive engineering world congress, No. 2003-01-3172.

Alfieri, E., Amstutz, A., \& Guzzella, L. (2008). Gain-scheduled model-based feedback control of the air/fuel ratio in diesel engines. Control Engineering Practice, 17(12).

Barba, C., Burkhardt, C., Boulouchos, K., \& Bargende, M. (2000). A phenomenological combustion model for heat release rate prediction in high-speed DI Diesel engines with common rail injection. In Proceedings of the society of automotive engineering world congress, No. 2000-01-2933.

Chang, K., Lavoie, G. A., \& Babajimopoulos, A. (2007). Control of a multi-cylinder $\mathrm{HCCl}$ engine during transient operation by modulating residual gas fraction to compensate for wall temperature effects. In Proceedings of the society of automotive engineering world congress, No. 2007-01-0204.

Chauvin, J., Corde, G., \& Petit, N. (2006). Constrained motion planning for the airpath of a Diesel HCCI engine. In Proceedings of the conference on decision and control.

Chauvin, J., Corde, G., \& Petit, N. (2007). Transient control of a Diesel engine airpath. In Proceedings of the American control conference.

Chauvin, J., Corde, G., Petit, N., \& Rouchon, P. (2008). Motion planning for experimental airpath control of a diesel homogeneous charge-compression ignition engine. Control Engineering Practice, 16, 23-24.

Chauvin, J., Corde, G., Vigild, C., Petit, N., \& Rouchon, P. (2006). Air path estimation on diesel HCCI engine. In Proceedings of the society of automotive engineering world congress.

Chiang, C. J., Stefanopoulou, A. G., \& Jankovic, M. (2007). Nonlinear observer-based control of load transitions in homogeneous charge compression ignition engines. In IEEE transaction on control system technology (Vol. 15, No. 3. pp. 438-448).

Chmela, F. G., \& Orthaber, G. C. (1999). Rate of heat release prediction for direct injection Diesel engines based on purely mixing controlled conditions. In Proceedings of the society of automotive engineering world congress, No. 199901-0186.

Haraldsson, G., Tunestål, P., Johansson, B., \& Hyvonen, J. (2003). HCCI combustion phasing with closed-loop combustion control using variable compression ratio in a multi cylinder engine. In Proceedings of the society of automotive engineering world congress, No. 2003-01-1830.

Haraldsson, G., Tunestål, P., Johansson, B., \& Hyvonen, J. (2004). HCCI closed-loop combustion control using fast thermal management. In Proceedings of the society of automotive engineering world congress, No. 2004-01-0943.

Heywood, J. (1988). Internal combustion engine fundamental. Mc Graw-Hill, Inc. 
Hillion, M., Chauvin, J., Grondin, O., \& Petit, N. (2008). Active combustion control of Diesel HCCI engine: Combustion timing. In Proceedings of the society of automotive engineering world congress, No. 2008-01-0984.

Hillion, M., Chauvin, J., \& Petit, N. (2008). Controlling the start of combustion on an HCCI Diesel engine. In Proceedings of the American control conference.

Kahrstedt, J., Behnk, K., Sommer, A., \& Wormbs, T. (2003). Combustion processes to meet future emission standards. In Motortechnische Zeitschrift (pp. 1417-1423).

Lafossas, F.-A., Marbaix, M., \& Menegazzi, P. (2007). Development and application of a OD D.I. Diesel combustion model for emissions prediction. In Proceedings of the society of automotive engineering world congress, No. 2007-01-1841.

Livengood, J., \& Wu, P. (1955). Correlation of auto-ignition phenomena in interna combustion engines and rapid compression machine. In Fifth international symposium on combustion (pp. 347-356).

Magand, S., Watel, E., Castagné, M., Soleri, D., Grondin, O., \& Devismes, S., et al. (2008). Optimization of a low NOx emission HCCI Diesel prototype vehicle. In Thiesel, conference on thermo- and fluid dynamic processes in diesel engines.

Milovanovic, N., \& Chen, R (2001). A review of experimental and simulation studies on controlled auto-ignition combustion. In Proceedings of the society of automotive engineering world congress, No. 2001-01-1890.
Olsson, J.-O., Tunestål, P., \& Johansson, B. (2001). Closed-loop control of an HCC engine. In Proceedings of the society of automotive engineering world congress, No. 2001-01-1031.

Rausen, D. J., Stefanopoulou, A. G., Kang, J.-M., Eng, J. A., \& Kuo, T.-W. (2004). A mean-value model for control of homogeneous charge compression ignition ( $\mathrm{HCCl})$ engines. In Proceedings of the American control conference.

Reveille, B., Miche, M., Jay, S., \& Henriot, S. (2004). Contribution of 3D CFD tools to the development and understanding of Diesel engines: Improving today's engines and designing tomorrow's power unit. In: Congrès le Diesel, Ecole Centrale Lyon.

Swan, K., Shahbakhti, M., \& Koch, C. R. (2006). Predicting start of combustion using a modified knock integral method for an $\mathrm{HCCl}$ engine. In Proceedings of the society of automotive engineering world congress, No. 2006-01-1086.

Walter, B., \& Gatellier, B. (2003). Near zero NOx emissions and high fuel efficiency Diesel engine: The NADI ${ }^{T M}$ concept using dual mode combustion. Oil and Gas Science and Technology, 58, 101-114.

Wang J. (2008). Air fraction estimation for multiple combustion mode diesel engines with dual-loop EGR systems. Control Engineering Practice, 16(12), 1479-1486, ISSN 0967-0661, doi: 10.1016/j.conengprac.2008.04.007. 